\title{
Investigation of the Oxidative Stress, the Altered Function of Platelets and Neutrophils, in the Patients with Peripheral Arterial Disease
}

\author{
Maria Kurthy et al ${ }^{*}$ \\ Department of Surgical Research and Techniques, Pecs University Medical School, Pecs
}

Hungary

\section{Introduction}

Ischemia reperfusion injury $(\mathrm{I} / \mathrm{R})$ is a relevant problem in case of myocardial infarction (Moens AL, Claeys MJ et al. 2005.), stroke, (Kato H and Kogure K 1999), coronary bypass surgery, (Bakkaloglu C, and Soyagir B, 2006), under thrombolysis, (Krumholz HM and Goldberger 2006), revascularization surgery of lower limb (Arato et al 2006., Laird IR 2003), balloon angioplasty (Weissand A.G. and Zahger AT 1999) and in every cases, when the physiological blood flow in the occluded vessels are restored (Falkensammer $\mathrm{J}$ and Oldenburg WA 2006), (Ferencz A et al 2004). Vessel closure and hypoxia can be caused by embolism (thrombus, tumour, fat, foreign body) stenotic arteriopathy, arterial spasm, compression, arterial thrombus, trauma, etc. During the exclusion of a segment of the vessels from the circulation, ischemia and acidosis appeared in the surrounding tissues. In case of the heart, when oxygen supply is inadequate, the respiration shift from aerobic fatty acid consumption and metabolism to anaerobic glycolysis, resulting in a reduced ATP production. The results of hypoxia in the metabolically active tissues (cardiac, skeletal muscle and neuronal tissues) are more profound than in other cell types. The cells are exposed to hypoxia try to adapt to the absence of oxygen, by switching their metabolism from aerobic to anaerobic. Finally this strategy leads to tissue damages and loss of cells too, as it can be seen in acute or chronic occlusive diseases, as well. The measures of the tissue injuries depend on the duration of hypoxia, the mass of tissues are involved, the ATP requirement of the cell types and the blood pressure of the patients. Under hypoxic condition the generations of reactive oxygen species (ROS), such as $\mathrm{O}^{2}$.-, $\mathrm{H}_{2} \mathrm{O}_{2}$, are increased. During normoxyc, physiological condition mitochondria generate low level of ROS by the respiratory chain. These are managed by natural antioxidants, such as manganese superoxid dismutase (SOD) in the mitochondria, or copper-zinc SOD in the inter-membrane space in the mitochondria, and in the cytosol, making the dismutation of superoxide anion

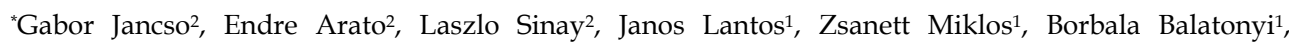
Szaniszlo Javor ${ }^{1}$, Sandor Ferencz ${ }^{1}$, Eszter Rantzinger ${ }^{1}$, Dora Kovacs, Viktoria Kovacs, Zsofia Verzar², Gyorgy Weber1, Balazs Borsiczky ${ }^{1}$ and Erzsebet Roth ${ }^{1}$

${ }^{1}$ Department of Surgical Research and Techniques, Pecs University Medical School, Pecs

${ }^{2}$ Department of General and Vascular Surgery of Baranya County Hospital, Pécs, Hungary
} 
generation to $\mathrm{H}_{2} \mathrm{O}_{2}$, which transformed further by catalase, glutathion plus glutathion peroxydase. Under hypoxic condition several sources of free radicals activated, e.g. the NADPH oxydase, xanthin oxidase, and others. ROS generated by hypoxia disrupts respiratory chain, causing a vicious cycle, manifested in modification in permeability transmission, loss of membrane potential, altering the function of mitochondrial complex I, III, and generating ubisemiquinon radical, which donates its electron to oxygen resulting in superoxyde anion. In reduced oxygen tension complex II switches its activity from succinate dehydrogenase to fumarate reductase (Henrich M et al, 2004.), Kolamunne RT et al 2011). Chronic sever hypoxia induces ATP depletion, and cell death. In the course of hypoxia, ATP generation decrees, exhausting the ATP sources, which responsible for the overflow of hypoxanthine, an ATP metabolite. Hypoxanthine in normoxyc condition metabolized further by xanthine dehydrogenase to xanthine (by means of nicotinamide adenine dinucleotide (NAD) as cofactor), but during hypoxia xanthin dehydrogenase converted to xanthin oxidase, which is unable to catalyse this conversion, but in the presence of high oxygen level in reoxygenation phase it continuously generates toxic ROS, because it uses oxygen as cofactor. ROS are effective oxidizing and reducing agents that directly damage cellular membranes, leading to impairment of membrane ion channels, disturbing cellular ionic balance resulting in cell swelling. ROS can activate leucocytes as well, and induce chemotaxis, cytokine release, leukocyte infiltration into the injured tissues, and due to endothelium dysfunction, a systemic reperfusion inflammatory response occurs. The most serious consequences of IR are the development of remote organ injuries in non-ischemic organs and can induce systemic inflammatory response injury (SIRS) or multiorgan failure syndrome (MOFS) which are responsible for of $20-40 \%$ of death in intensive care units (Levy $\mathrm{JH}$, and Tanaka KA 2003). Tough reconstruction of the flow in the occluded vessels is not without risk, because of the generated volume, pressure and metabolic load, accompanied by further tissue damages resulting in the so-called reperfusion injury.

The main components of the molecular pathophysiological cascades are the activated circulating cells, first of all the white blood cells (WBC), mainly the neutrophils, due to their intensive free radical production, but, thrombocytes (PLT), red blood cells (RBC), and the cells of the vessel wall (endothelial cells and smooth muscle cells) also participate in the free radical production and the tissue damage (Roth and Hejjel 2003). In the early reperfusion the release of inflammatory cytokines, such as tumor necrosis factor alpha (TNF) increase too. These events together with the elevated $\mathrm{Ca}^{2+}$ levels inside the attached cells threat the integrity of the whole organism, destroying the crucial macromolecules, proteins, lipids and nucleic acids (Arato et al. 2005), (Blaisdell FW 1989).

Reactive oxygen species are Janus-faced agents. They have important role in eliminating pathogen microorganisms from the body, and can regulate cell growth and differentiation. ROS can act as important signalling molecules, in the circulation and participate in the maintenance of intra- and extracellular milieu. They can induce redox sensitive transcription factors, regulate redox sensitive signalization cascades and can act as secondary messengers (Kathy K et al 2000), (Dröge W, 2002). Oxygen free radicals can act as second messengers and they are able to influence the function of enzymes, and transcription factors, leading to the induction of genes are sensitive to them ( $\mathrm{Li} \mathrm{W}$ et al 2008). Their intra- and extracellular levels are regulated by SOD and catalase (the enzymes are present in almost all living organisms are exposed to oxygen) and other antioxidant, respectively. On the other hand they can cause endothelial dysfunction due to eliminating vital nitrogenous monoxides 
(NO), which are absolutely necessary for the endothelium dependent relaxation of the vessels (Moncada et al 1991), for the proper function of cardiomyocytes (Umar S, van der Laarse A. 2010), and for the physiological function of circulating cells, such as thrombocytes (Massberg S 1998) and leukocytes, and red blood cells. It can be stated that free radicals are both our friends and enemy at the same time (Downey JM, and Cohen MV 2008).

It is very difficult to monitor the cellular processes which influence the outcome of the surgical interventions, or serves as a marker of the postoperative events. A huge amount of data emerged for the characterization of ischemia reperfusion injury, but function of platelets and other circulating cells or their interaction with each other or with endothelial cells has been hardly investigated (Buchholz AM, Bruch L 2003.). Limitation of reperfusion injury is inevitably important to prevent tissue damages, manifested in apoptosis, necrosis or both, and frequently occurred after restoration of circulation after stroke, myocardial infarction, organ transplantations, and in all types of revascularization surgeries. There are pharmacologic tools, and protective processes, which can reduce IR injury. Antioxidants, such as N-acetylcysteine, vitamin E, mannitol, thiols, alkaloids and endogenous antioxidants, such as superoxide dismutase, reduced glutathion, glutathione reductase, catalase, or ion chelators functions due to inactivation of free radicals, which are key element in IR induced tissue damages (Arato et al 2010), (Peto K, et al 2007), but leukocyte depletion, anti-cytokine or leukocyte adhesion molecule monoclonal antibody therapies ended with conflicting results (Arato et al 2010) (Loberg AG et al 2011). Among other effective possibilities, ischemic postconditioning is one of the most effective processes in reducing IR caused damages, which was first introduced by Vinten-Johansen's group in 2003. The main essence of application of short (some seconds) repetitive interruption of early reperfusion by brief ischemic episodes resulting in reduced infarct size in the heart, diminished tissue edema, reduced infiltration of leukocytes into the area of injury, as they were improved in animal studies (Vinten-Johansen J 2007).

Angioplasty with or without vascular stenting is an effective method, was developed by Dotter and Judkins (Misty $\mathrm{M}$ et al 2001) to reconstruct the proper flow within the narrowed or occluded vessels. The procedure is carried out mainly in the coronary arteries, but it is frequently applied in other parts of the circulation. The procedure itself is a typical example of I/R injury was characterized above, with main risks of endothelium dysfunction and reocclusion due to thrombus formation and/or smooth muscle proliferation. The potential role of the circulating cells, such as PLT, WBC, and RBC in the vessel closure is intensively studied, and their interactions with the components of vessel wall, mainly with the smooth muscle cells and the endothelial linage have special attention (Ming Wei Liu et al 1989). Platelet leukocyte interaction is also investigated, because of their unique role in reocclusion (Szabo S. et al 2005).

In the present study we aimed to investigate the function of circulating cells in the course of acute (emergency) and elective revascularization surgery in lower limb of patients with Peripheral arterial disease (PAD). In our studies thrombocyte function, antioxidant and prooxidant status were investigated in two groups of patients, who were scheduled to elective revascularization surgery (Elective) and were compared to the patients with acute vessel closure and were undergone revascularization surgery in emergency, 4-6 hours after of vessel closure (Acute). Data obtained in the two patients groups were compared to the same parameters of healthy veterinary blood donors (Control). Patients of the two groups (Acute and Elective) have other chronic diseases too, such as diabetes mellitus. Diabetes is a disease when patients have high blood sugar concentration due to the inadequate production: DM1, or 
inadequate effects on the tissues of otherwise physiological or high level of circulating insulin: DM2. In the second series of experiments, thrombocyte function and prooxidant/antioxidant status of DM1 and DM2 patients with PAD were also investigated. In vitro effects of exogenous insulin (Actrapid Insulin (Novo-Nordisk) In 0, 40, 80, $160 \mu \mathrm{U} / \mathrm{ml}$ ) were also investigated on collagen induced platelet aggregation and phorbol - 12 myristate-13 acetate (PMA) induced reactive oxygen species (ROS) production in whole blood.

\section{Materials and methods}

Patients selection and investigation in this randomized, open, prospective studies was carried out according to the Helsinki declaration (1996), considering the statute of Hungarian Ministry of Health (32/2005. (VIII:26), with the permission of the local ethical board of the Pecs University, Medical School. (Permission No.: 2498).

\subsection{The first series of experiments}

The aim of this study was to investigate the effect of the duration of hypoxia on the thrombocyte function, free radical production and antioxidant/prooxidant statuses of the patients who were undergone revascularization surgery of lower limb.

Patients: Two groups of patients were investigated:

1. Acute group: $n=12 ; 9$ males and 3 female, age: 58.1 \pm 7.3 years, suffered from ischemia 4-6 hours before revascularization surgery of lower limb because of seriously ischemic extremities due to embolism, acute arterial thrombosis or rupture of infrarenal artery before the surgery. They were undergone revascularization surgery in emergency.

2. Elective group $n=10$, ( 6 male 4 female) were scheduled to elective revascularization surgery because of chronic obliterative arterial stenosis. Ischemia was diagnosed by angiography, and Doppler test.

Other chronic diseases accompanied by PAD in our patients are summarized in Table 1.

Surgical interventions were carried out in General and Vascular Surgery Department of Baranya County Hospital (Pecs; Hungary), and were performed in spinal anaesthesia, with 43.8 \pm 17 min ischemic time. Patients of both groups received similar anticoagulant and antiplatelet therapy (at least $75 \mathrm{mg}$ Aspirin) and low molecular weight heparin was also prescribed in the perioperative period. Medication of the patients is summarized in Table 2.

\begin{tabular}{|c|c|c|}
\hline Disease & Acute group & Elective group \\
\hline Hypertension & $6 / 12$ & $8 / 10$ \\
\hline Ischemic heart disease & $3 / 12$ & $4 / 10$ \\
\hline Diabetes mellitus & $4 / 12$ & $5 / 10$ \\
\hline Lung complications & $4 / 12$ & $4 / 10$ \\
\hline Smooking & $5 / 12$ & $4 / 10$ \\
\hline
\end{tabular}

Table 1. Chronic diseases accompanied with PAD in the first series of the study

Blood sampling: Venous blood samples were obtained by venipuncture. Samples of 10 healthy blood donors (Blood Donation Center of Pecs, Hungary) served as Control. Venous blood samples of the two patients groups were obtained before and 2 and 24 hours and one week after the surgery. Blood samples were collected into three Vacutainer tubes containing trisodium citrate $(3.8 \%)$ or K3-EDTA $(7.5 \%)$ (Becton Dickinson, UK). Informed consents were obtained from all patients and volunteers participated in the study. 


\begin{tabular}{|c|c|c|}
\hline Groups of medicine & Acute & Elective \\
\hline $\begin{array}{c}\text { PLT aggregation inhibitors } \\
\text { (Aspirin protect or Astrix) }\end{array}$ & $12 / 12$ & $10 / 10$ \\
\hline $\begin{array}{c}\text { Anticoagulant } \\
\text { (perioperative) }\end{array}$ & $12 / 12$ & $10 / 12$ \\
\hline Antihypertensive & $6 / 12$ & $8 / 10$ \\
\hline Antidiabetic & $4 / 12$ & $5 / 10$ \\
\hline Others & $12 / 12$ & $10 / 10$ \\
\hline
\end{tabular}

Table 2. Medication of patients with PAD in the $1^{\text {st }}$ series of the study

Laboratory measurements: were carried out in Department of Surgical Research and Techniques of Pecs University Medical School, Hungary. Hematologic measurement: red and white blood cell numbers, haemoglobin concentration, platelet numbers were measured by Minitron automatic analysator (Diatron LTD Budapest, Hungary). Platelet aggregation measurements:

1. in platelet rich plasma (PRP), according to Born's turbidimetric method (Born 1965a), Born et al 1965b), by means of Carat aggregometer (Carat Diagnostic ltd, Budapest, Hungary), using ADP $(5 \mu \mathrm{M}$; and $10 \mu \mathrm{M})$ and collagen $(2 \mu \mathrm{g} / \mathrm{ml})$ as inductors. Aggregation was followed for 8 minutes after its induction and expressed in $\%$.

2. in whole blood was measured by the method of Ingerman-Wojenski and Silver by Chrono-log lumino-aggregometer (type 560VS, USA), according to the user's manual of the instrument (Ingerman-Wojenski CM and Silver MJ), using the same inductors as was used in PRP. In whole blood platelet aggregation was measured by impedance, and expressed in Ohm, and was followed for six minutes from its induction.

Measurement of main antioxidants: $S O D$ is an ancient antioxidant enzyme of pro- and eukaryotic organisms, containing metal $(\mathrm{Cu}, \mathrm{Zn}, \mathrm{Fe}, \mathrm{Mn} \mathrm{Ni}$, respectively) in its active centre, and it has several isoforms, which can be found intra- and extracellularly, in almost all living creature, as well. Measurement of SOD activity was carried out by the method of Misra and Fridovich (Misra and Fridovich 1972). Reduced glutathione (GSH) levels were determined in plasma were obtained after centrifugation of anticoagulated whole blood, using Ellman's reagent (Sedlak and Lindsday 1968). GSH cystein is able to neutralize free radicals by donating one electron and stabilizes them. In the course of this reaction it became reactive, as well, but an other GSH can neutralize it, forming GSSG, which will be regenerated to GSH by glutathione reductase. Plasma proteins (such as albumin) contain sulphydril groups, as well and exert remarkable antioxidant capacity though its - $\mathrm{SH}$ groups, was measured also.

Measurement of prooxidants: Reactive oxygen species (ROS) was measured in the mixture of whole blood $(20 \mu \mathrm{l})$ and phosphate buffered saline $(1400 \mu \mathrm{l})$ by chemiluminometric, kinetic method, by means of Chrono-Log lumino-aggregometer. The main sources of ROS in the blood are leukocytes. ROS production was induced in whole blood by phorbol -12miristate-13-acetate (PMA) and was made detectable by luminol (Arato et al 2010b).) Malondialdehyde $(M D A)$, the main lipid peroxidation marker, which signs the polyunsaturated fatty acid peroxidation of the biological membranes. It was measured in anticoagulated whole blood and in plasma (Ohkawa H (1979). Myeloperoxidase (MPO) produces hypochlorous acid $(\mathrm{HOCl})$ from hydrogen peroxide $\left(\mathrm{H}_{2} \mathrm{O}_{2}\right)$ and chloride anion $\left(\mathrm{Cl}^{-}\right)$(or the equivalent from a non-chlorine halide) during the neutrophil's respiratory burst. 
It requires hem as a cofactor. Furthermore, it oxidizes tyrosine to tyrosyl radical using hydrogen peroxide as an oxidizing agent. MPO level was measured in plasma, according to the method of (Xia and Zweier 1997).

\subsection{The second series of experiments}

\section{The aim of this study}

Insulin resistance and diabetes mellitus are causal or worsening factors in the peripheral arterial diseases (Jude EB 2001). In the second part of the study we intended to investigate thrombocyte function parallel with antioxidant prooxidant status of ambulant diabetic (DM1 and DM2) patients with PAD were under the care of General and Vascular Surgery Department of Baranya County Hospital (Pecs; Hungary). Eleven healthy volunteers of Blood Donation Centre of Pecs served as controls

\section{Methods}

This study involved 24 patients with DM1 (18 male and 6 female; age: $62 \pm 2.3$ year), and 22 with DM2 (18 male and 4 female; age: 65,7 \pm 3.7 ) with PAD. Healthy blood donors served as control (8 male and 2 female; age: $33 \pm 6.7$ years). Anticoagulated whole blood of ambulant patients and volunteers were used. Informed consents were obtained from all participants. Regular medication of the two patients group is summarized in Table 3.

\begin{tabular}{|l|c|c|}
\hline Medication & DM1 & DM2 \\
\hline $\begin{array}{l}\text { Platelet aggregation inhibitors } \\
\text { (Aspirinprotect or Astrix) }\end{array}$ & $24 / 24$ & $22 / 22$ \\
\hline Anticoagulant (Syncumar) & $4 / 24$ & $4 / 22$ \\
\hline Anticoagulant (LMWH) & $12 / 24$ & $10 / 22$ \\
\hline Antihypertensive & $18 / 24$ & $18 / 22$ \\
\hline Insulin & $24 / 24$ & $2 / 22$ \\
\hline Oral antidiabetic & $0 / 24$ & $20 / 22$ \\
\hline Other & $24 / 24$ & $22 / 22$ \\
\hline
\end{tabular}

Table 3. Medication of the DM1 and DM2 patients.

\section{Parameters to be measured}

Clinical chemistry data: Glucose triglyceride, cholesterol was measured by commercial kits (Diagnosticum Ltd Budapest) by photometric method. Platelet aggregation was measured in whole blood and in PRP. PMA induced ROS production; endogenous antioxidant and prooxidant status of these patients were measured as it was described above. Platelet aggregation: Platelet aggregation was measured in PRP and in whole blood as it was described above. In the latter case area under the aggregation curves were calculated as well, using Origin 6.0 data analyzing and graphing software. Collagen induced platelet aggregation, and PMA induced ROS production were measured in the presence of $0,40,80,160 \mu \mathrm{U} / \mathrm{ml}$ insulin (Actrapid), too. Statistical analyses: Student's paired and unpaired t-test and one way analysis of variance were used. Differences were considered significant, when $\mathrm{p}$ was less than 0.05 . The results were expressed as mean \pm SD or in percentage. 


\section{Results}

\subsection{Results of the first series of experiment}

\subsubsection{Results of clinical chemistry measurements}

Red blood cell numbers were similar in the three groups, but haemoglobin concentration was significantly lower and leukocyte number was higher in Acute group, compared to the Elective and Control ones, in the course of the study

\subsubsection{Platelet aggregation in platelet-rich plasma}

ADP and Collagen were selected as aggregation inductors. These agents were used to control the efficacy of the two most frequently used groups of antiplatelet drugs, the cyclooxygenase (COX) inhibitors and adenosine diphosphate (ADP) receptor antagonists.
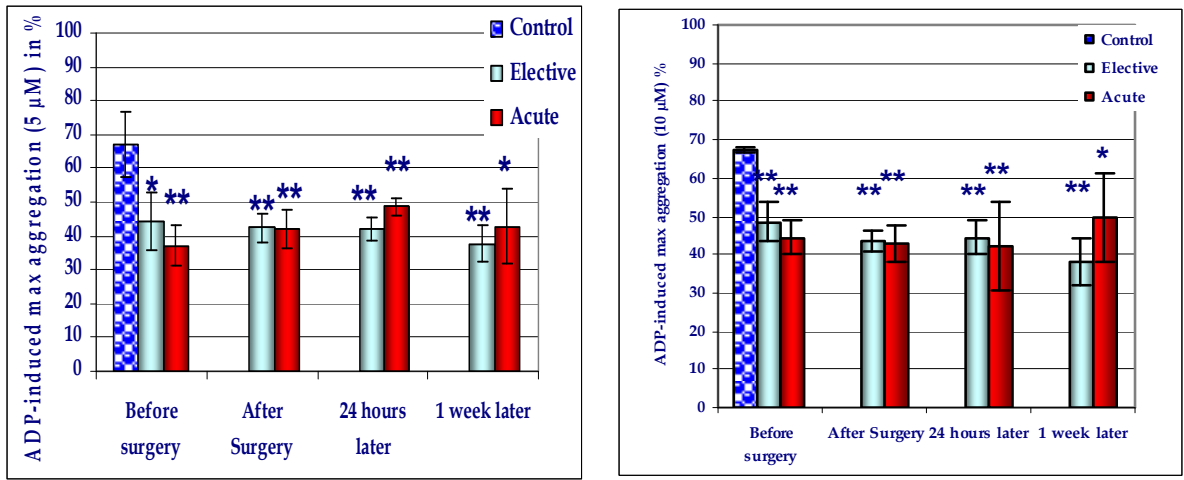

Fig. 1. ADP (5 and $10 \mu \mathrm{M})$ induced aggregation in platelet rich plasma. Antiplatelet therapy seemed to be effective in both patients groups using 5 and $10 \mu \mathrm{M}$ ADP, as inductor in PRP. ${ }^{*}=p<0.05$ vs. Control, ${ }^{* *}=p<0.01$ vs. control.

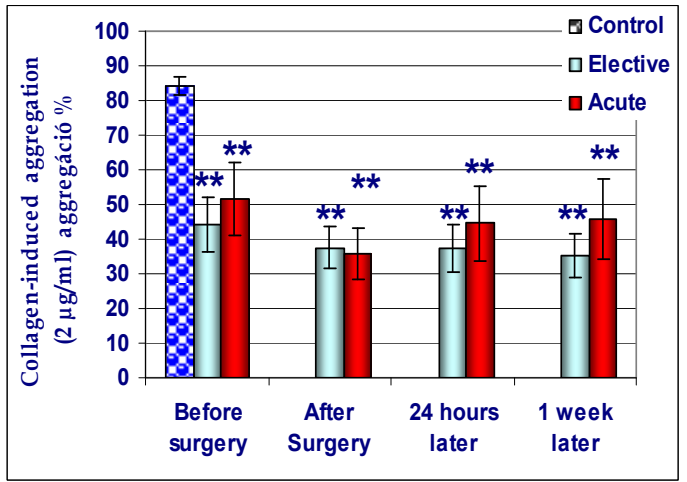

Fig. 2. Maximum values of collagen $(2 \mu \mathrm{g} / \mathrm{ml})$ induced platelet aggregation in PRP, compared to Control. ${ }^{*}=\mathrm{p}<0,05,{ }^{* *}=\mathrm{p}<0.01$ compared to controls. 
In figure 1 and 2 the ADP- and in figure 3 the collagen induced aggregation maximums were summarized, and compared to the values of healthy subjects. According to our data antiplatelet therapy received by both patients groups were effective on the level of isolated thrombocytes in the whole observation time. Platelet aggregation in Control group was within the normal range either ADP or collagen was used as inductors (61-91\% of ADP, and 64-92 of collagen), contrarily in both groups of patients a significantly reduced response to $\mathrm{ADP}$ and Collagen were measured, signing an effective anti-platelet therapy.

\subsubsection{Investigation of platelet aggregation in whole blood}

\subsubsection{ADP induced platelet aggregation in acute and elective groups}

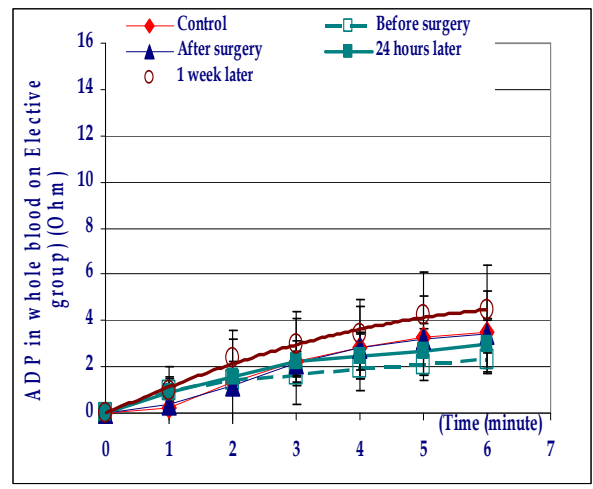

Fig. 3. ADP induced platelet aggregation in Elective group, compared to Control (red line)

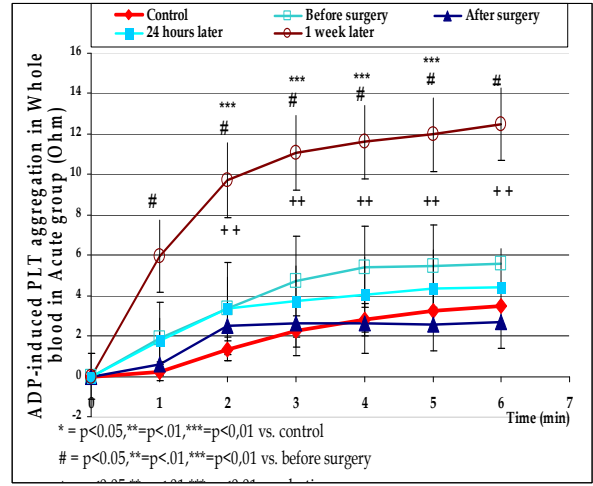

Fig. 4. ADP induced aggregation in Acute group, compared to Control (red line).

ADP induced platelet aggregation in whole blood was similar in Acute and Elective and Control groups before the surgery. In the Elective group ADP induced platelet aggregation did not changed significantly in the course of the study. In the Acute group a significant gradual increase was observed in the function of time, with a four times increase at the end of the week (Figure 4). 


\subsubsection{Collagen induced aggregation in whole blood}

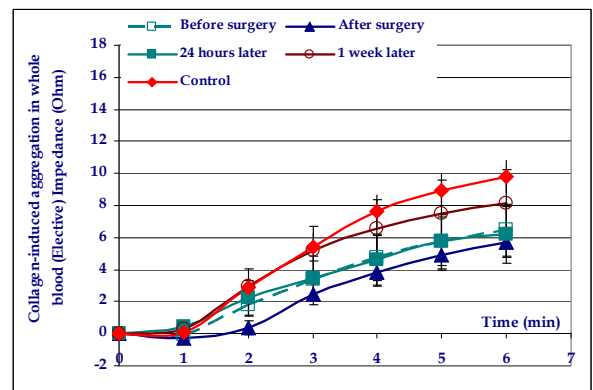

Fig. 5. Collagen induced platelet aggregation in Elective group.

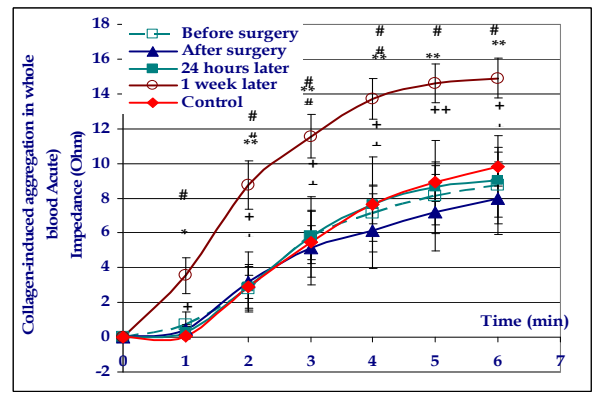

Fig. 6. Collagen induced aggregation in whole blood in Acute group.

In whole blood of healthy subjects, the collagen induced platelet aggregation started with one minute delay. In the patient groups, collagen induced aggregation started without delay, mainly in Acute group, one week after the surgery. Application of the inductor in this case resulted in an immediate induction of platelet aggregation. The effect of antiplatelet therapy was detected in platelet- rich plasma was missed in whole blood.

\subsubsection{Investigation of antioxidants}

\subsubsection{GSH level}

Before surgery GSH levels were similar in the three groups. In patients groups a transient reduction occurred 2 hours after and one day after the surgery, but returned to the baseline level one week after the surgery.

\subsubsection{Plasma thiol groups}

Before the surgery the plasma SH-group concentration of the patient groups did not differed from each other or the healthy controls, but a transient, significant reduction was measured 2 hours and 24 hours after surgery in both patients groups, which returned to the normal level 1 week later. 


\subsubsection{SOD activity}

Before surgery SOD activity was lower in both patients groups, compared to Control, however SOD activity in Elective group was higher than in Acute group, and remained unchanged during the study. In Acute group SOD level decreased further 24 hours after the surgery. SOD levels of patients groups remained below the normal range in the course of the whole study (Figure 7.)

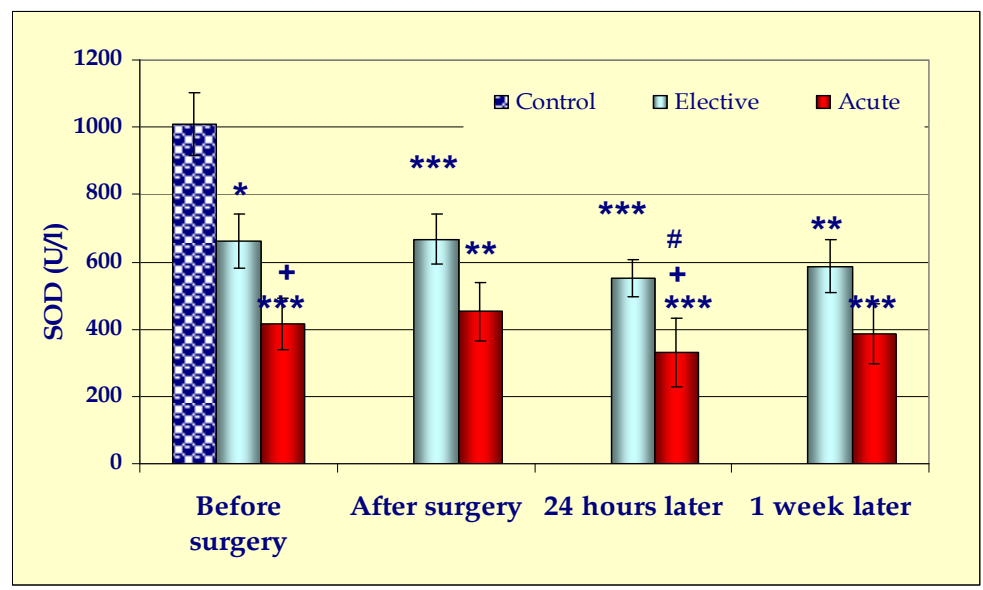

Fig. 7 . Changes in SOD activity. ${ }^{*}=p<0.05,{ }^{* *}=p<0.01,{ }^{* *}=p<0.005,+=p<0.05$ vs. elective, $\#=\mathrm{p}<0,05$ vs. before surgery

Before surgery SOD activity in both patients groups were lower compared to healthy volunteers. This low level decreased further significantly $n$ Acute group until the $24^{\text {th }}$ hour of reperfusion and remained in this low level during the study. In elective group SOD level was on a constant low-level during the study. I/R injury was described almost 50 years ago, but the correct mediation, the way of prevention or treatment is under investigation in nowadays, as well. The inflammatory responses can be detected following reperfusion varies greatly and depends on the time and severity of ischemia, as it was measured in our cases too. Restoration of blood flow of ischemic tissues initiates a chain reaction of complications which can categorize into two main groups: regional and systemic. In our case restoration of blood flow in lower limb, generated a systemic response, which had been detected in blood samples (in serum, haemolysate, plasma) obtained in a great distance from the intervention.

\subsubsection{Investigation of prooxidants}

\subsubsection{PMA induced free radical production}

Before surgery PMA induced ROS production was higher in Acute than in Elective and Control groups. This value elevated further in the course of the study. Free radical generation was characterized with four parameters: 1 . the lag-time: the time elapsed between the induction and the beginning of the free radical production, 2. maximum of free radical 
production corrected to the WBC numbers, 3. the Slope: the rate of rise of the ascending part of the free radical generation curves and the WBC numbers (Figure 8.).
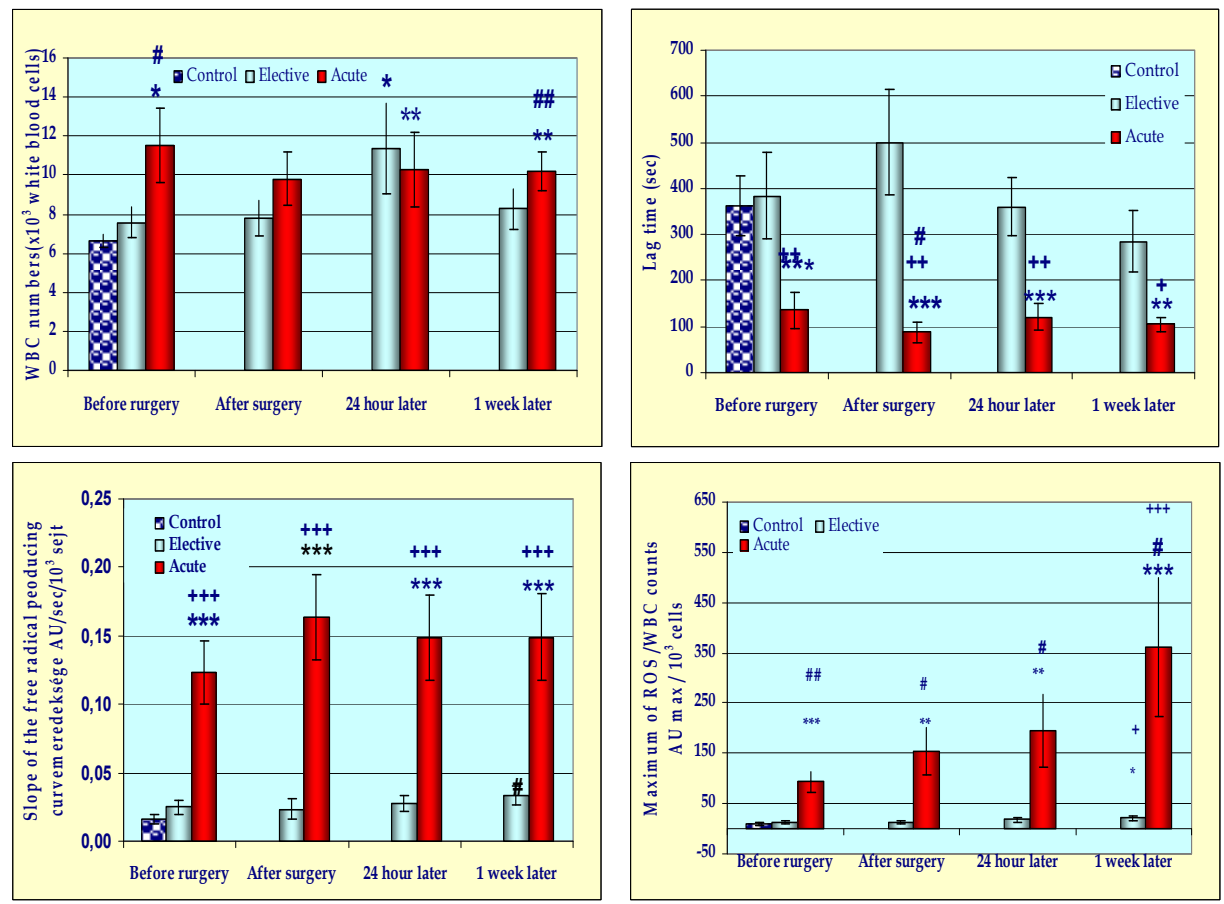

Fig. 8. Upper left panel: white blood cell numbers, upper right panel: lag time, bottom left panel: slope of free radical curve, bottom right panel: maximal free radical production. $* * *=0.001$ vs. control, $+++=p<0.001$ vs. elective, $\#=p<0.01$ vs. before surgery).

In Acute group WBC numbers were significantly higher (upper left panel) and Lag time was significantly shorter (upper right panel) before and one week after the surgery, than the similar values in Elective and Control Groups $\left({ }^{*}=p<0.05\right.$ vs. Control, $\#=p<0.05$ vs. Elective groups). Slope of the free radical producing curves became steeper in acute and elective groups, signing that more and more active WBC are present before and one week after the surgery, but in Acute group this free radical generation was significantly higher, than in the other two groups. The maximum of free radical production continuously elevated both in acute and in elective groups, but these elevation in acute group was several times higher than it was measured in elective group (figure 8.).

\subsubsection{Investigation of lipid peroxidation due to measurement of MDA in plasma and in red blood cell haemolysate}

It is a well known fact, that one of the main consequence of long-lasting atherosclerosis is the significant decrease in the polyunsaturated fatty acid (PUFA) content of the membranes, due to saturation of the membrane lipids which responsible for the rigidity of the membranes. MDA is one of the lipid peroxydation end products, generated in the course of 
free radical induced peroxydation of PUFA. MDA is frequently used as a lipid peroxydation marker in biological tissues.
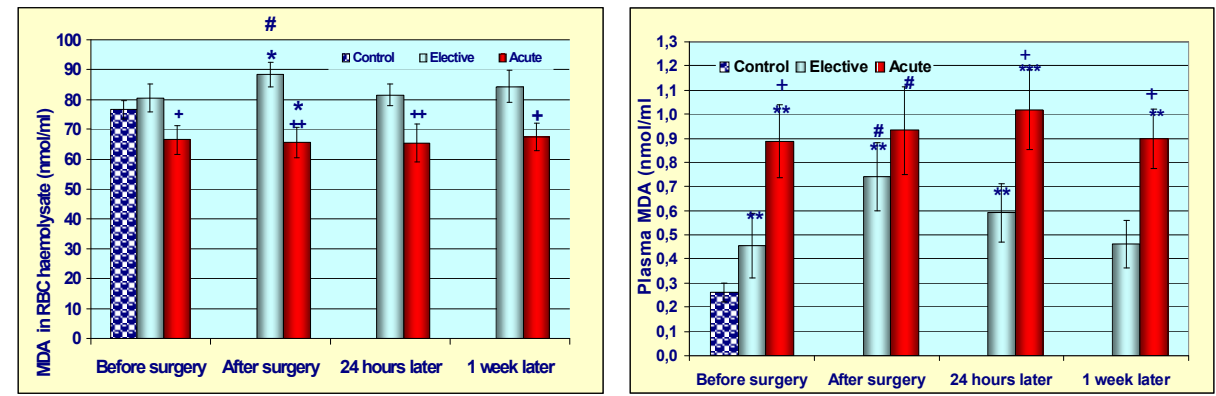

Fig. 9. MDA level in red blood cell (RBC) hemolysate (left panel) and in plasma (right panel $){ }^{*}=p<0.05$ vs. Control, ${ }^{* *}=p<0.01$ vs. Control, ${ }^{* * *}=p<0.0051$ vs. Control $+=p<0.05$ vs. Elective, $\#=\mathrm{p}<0.05$ vs. before surgery

Surprisingly, in our case MDA concentration of erythrocyte membrane remained in a standard, relatively low level during the whole study, in the Acute group. We speculated about the background of this phenomenon, and finally we concluded that the long-lasting hypoxia preceeded the surgery may exhausted of the PUFA contents of the lipidmembranes. At the same time, plasma MDA of Acute group (right panel) were significantly higher than in Elective and Control groups, and elevated further 24 hours after the surgery, and returned to the baseline one week after the surgery. In Elective group a bell-shaped elevation appeared which peaked 2 hours after surgery (Figure 9. right panel).

\subsubsection{Changes in MPO}

In spite of MPO have not been evaluated in routine clinical chemistry studies, according to a recent study of Brevetti and coworkers its elevated level, but not C-reactive protein, predicts cardiovascular risk in peripheral arterial disease (Brevetti $G, 2008$ ). According to an other study it is a marker of myocardial infarction too. The base-line myeloperoxidase level independently predicts the risk of major adverse coronary events within 30 days.

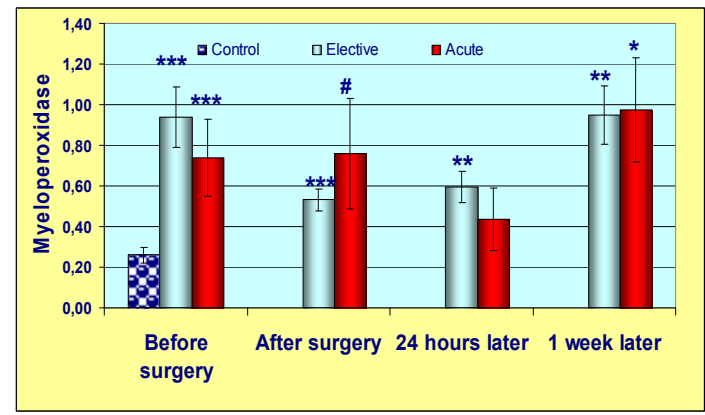

Fig. 10. Myeloperoxidase level in Control, Elective and Acute groups. MPO level both in Elective and Acute groups were significantly higher than in Control before surgery, than after a transient decrease in the postoperative period returned to the preoperative level. 
(Brennan ML et al 2003). MPO is a hydrogen peroxide oxidoreductase, specifically found on mammalian polymorphonuclear leukocytes (PMN), responsible for the bactericidal capability of these cells. PMN activation and mediator release are partially responsible for the morbidity and mortality of revascularization of ischemic lower limb, regardless of the mode of intervention, surgery or application of thrombolytics.

\subsubsection{Conclusion of the first series of the experiments}

Ischemia/reperfusion injury, accompanied by revascularization surgeries of lower limb, was in the focus of the present study. This problem has great importance in the clinical practice because of its poor outcome (postoperative mortality is 15-60\%). Tissue injury appears not only under ischemia, but after restoration of the blood flow in the formerly ischemic areas, due to the reperfusion injury, as well (Yasin) NM et al. 2002), (Arato et al 2009). Ischemia reperfusion injury of lower limb is accompanied by muscle changes with progressive micro-vascular damage, and affects all circulating cells (RBC, WBC, and PLT), as well. These cells are in connection with each other and with cells of the vessel walls, too. Inflammatory response following reperfusion varies greatly, and depends on the time and severity of ischemia. According to our results in accordance with several other studies, the duration and severity of ischemia is proportional to the damage occurred after it. Studying thrombocyte function and antioxidant prooxidant status of our unique patient groups, several new aspects of ischemia reperfusion injury were revealed. Peripheral arterial disease is a common progressive disorder that attaches the circulation of the legs, particularly in people over 55 years, strengthening in these patients the greatly increased risk of heart attack or stroke, and of dying within a decade. Several aspects of the problem were intensively studied, but platelet function during the restoration of the circulation of ischemic lower limb was hardly investigated before. It was revealed in this study that an effective antiaggregating therapy was applied in these patients, and effectively reduced the aggregation induced by ADP and collagen in PRP, but this reduction in whole blood was completely disappeared, both in ADP and collagen induced aggregation in Acute and Elective groups too. Above this a highly significant increase in platelet aggregation was measured in whole blood, in response to both types of inductors, one week after the surgery in Acute group. We concluded on the basis of our result that the long-lasting hypoxia is responsible for the increased PLT aggregation in whole blood, as the consequence of the shift of the antioxidant-prooxidant balance to the prooxidant direction lead to the increased response to aggregation inductors.

\subsection{Results of the second series of experiments 3.2.1 Clinical chemistry data}

Monitoring thrombocyte function and antioxidant prooxidant status of diabetic patients with peripheral arterial disease is inevitably important, because of the increased risk of complication. Patients suffering from both diabetes and PAD are at risk of developing critical limb ischemia, ulceration and potentially requiring limb amputation. In addition, diabetes complicates surgical treatment of PAD and impairs vascular functions. The presence of diabetes increases the frequency of intermittent claudication. The relative risk of amputation in diabetic population is 12,4-fold higher compared to the non diabetic patients $(95 \%, 10,9-14,9)$, and this value doubles above 65 years. Diabetes increases the sensing of shear stress and the response to vasoconstrictor stimuli, reducing the recruitment and dilatation of collateral arteries (Brennan ML et al 2010). 


\begin{tabular}{|l|c|c|c|}
\hline $\begin{array}{l}\text { Group of } \\
\text { patients }\end{array}$ & Glucose & Triglyceride & Cholesterol \\
\hline DM1 & $11.4 \pm 1.6$ & $1.9 \pm 0.3$ & $4.3 \pm 0.6$ \\
\hline DM2 & $7.3 \pm 0.7$ & $4.3 \pm 1.4$ & $5.2 \pm 0.7$ \\
\hline Healty & $4.82 \pm 0.27$ & $1.1 \pm 0.15$ & $4.2 \pm 0.5$ \\
\hline Normal values & $4.2-6.1 \mathrm{mmol} / 1$ & $0.4-1.7 \mathrm{mmol} / 1$ & $3.7-5.2 \mathrm{mmol} / 1$ \\
\hline
\end{tabular}

Table 4. Clinical Chemistry of Control subjects and DM1 and DM2 patients.

Glucose and triglyceride levels of diabetic patients were higher than the normal values. The mean value of cholesterol level was within the normal range, but individually high values were measured, as well.

\subsubsection{Investigation of platelet aggregation}

\subsubsection{Investigation of PLT function in platelet rich plasma}

Investigation of platelet function by turbidimetric method in PRP is a more frequently used method, than impedance measurement in whole blood. Our own investigations focused our attention on the usefulness of the parallel measurements. There are several advantages using both methods parallel, e.g. in PRP platelet function can be measured independently from other circulating cells. It is very advantageous if we investigate the effect of antiplatelet drug in a specific direction. Contrary, in whole blood the effects of the other components of circulating cells of blood (leukocytes, red blood cells) can be studied together.

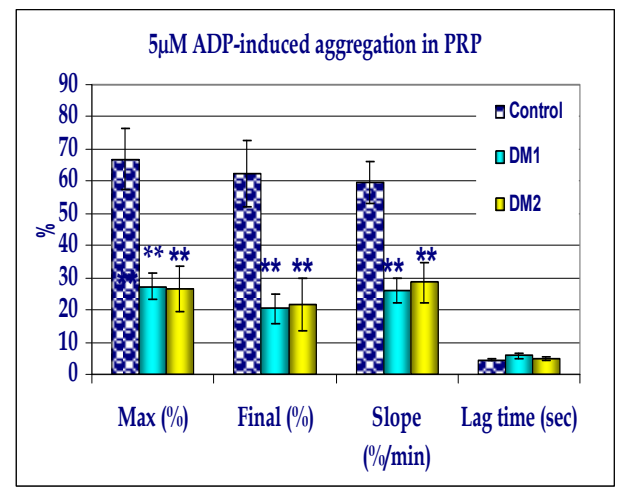

Fig. 11. ADP induced platelet aggregation in PRP of diabetic patients with PAD.

All parameter were measured in DM1 and DM2 Patients were reduced, compared to Control. In DM2 patients Slope of the aggregation curve was significantly higher compared to Elective groups. 


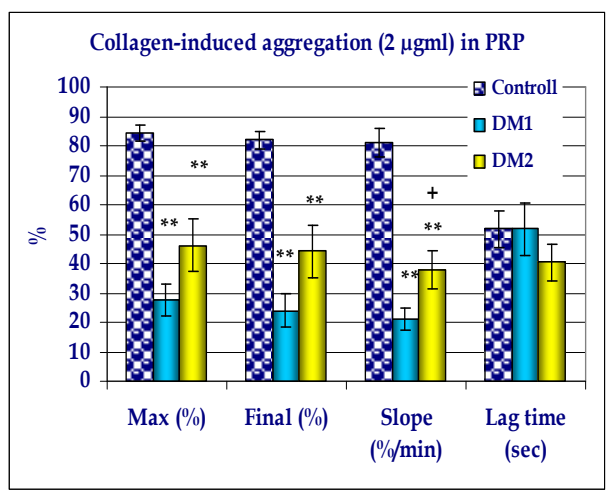

Fig. 12. Collagen induced platelet aggregation in PRP of diabetic patients with PAD.

3.2.2.2 Investigation of ADP induce platelet aggregation in whole blood in control and diabetic patients with PAD

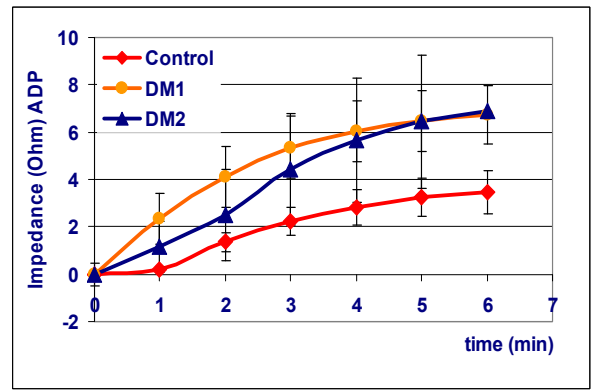

Fig. 13. ADP induced platelet aggregation of healthy and diabetic patients with PAD in the function of time. However patient's data were higher in every time points compared to Control, significant difference can't be detected.

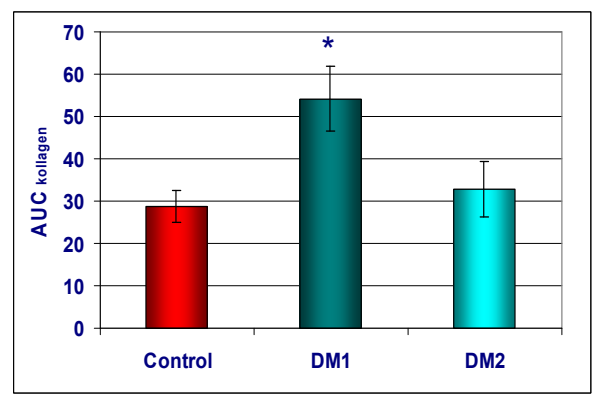

Fig. 14. Area under the ADP induced platelet aggregation curves (AUC). AUC of patients with PAD were significantly higher $(\mathrm{p}<0.05)$, than that of Control 


\subsubsection{Investigation of PLT function in whole blood in control and diabetic patients} collagen induce platelet aggregation in whole blood

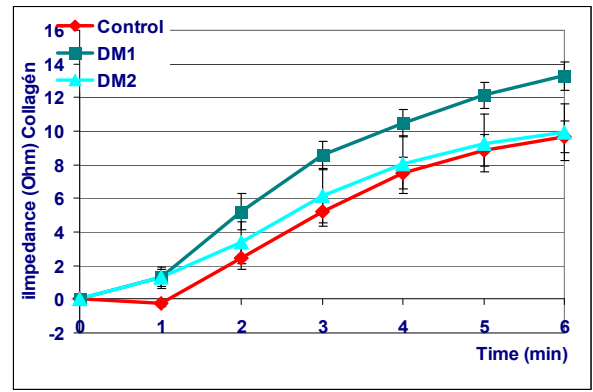

Fig. 15. Collagen induced platelet aggregation in whole blood of healthy and diabetic subjects with PAD in the function of time. Platelet aggregation of diabetic patients was higher in each point of times, but significant difference has not been observed among the groups.

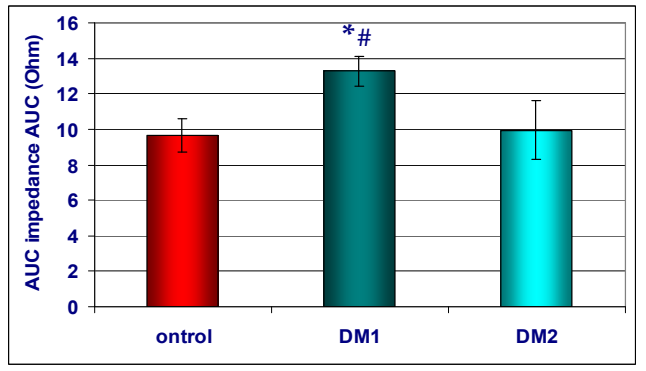

Fig. 16. AUC of the platelet aggregation curves of healthy and diabetic patients. Significant differences were measured among DM1 and DM2 groups, compared to each other (\#)., and between DM1 and Control.

\subsubsection{Antioxidant and prooxidant levels}

Plasma GHS levels were similar in the three groups, however SOD activity was significantly lower in both patients groups, compared to Control (Figure 17). WBC numbers in the DM1 group was the double and ROS production/103 WBC was 20 times higher in DM1 group than in Control and was double of the DM2 (Fig.18)

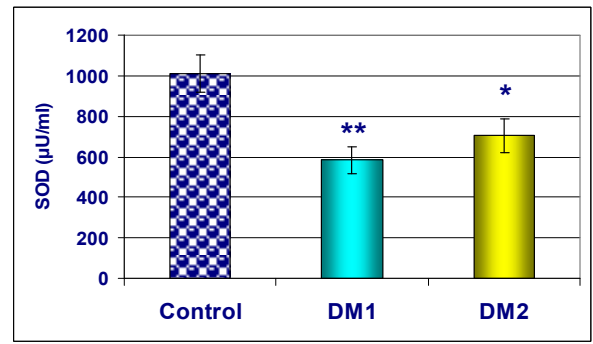

Fig. 17. SOD activity was significantly lower in patients groups than in Control. 


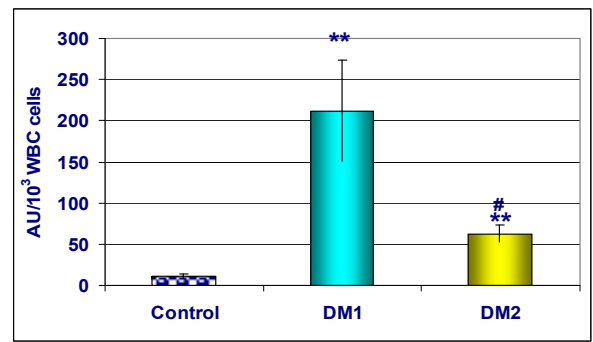

Fig. 18. PMA induced ROS production was higher in patients then in Control

\subsubsection{In vitro effects on insulin on platelet aggregation in whole blood}

3.2.4.1 In vitro effect of actrapid insulin on collagen induced platelet aggregation in whole blood of healthy volunteers, DM1 and DM2 patients with PAD was investigated

Actrapid insulin exerts its effect within a short time in patients too, that was the reason why we chose this. Platelet aggregation was expressed in Ohm, and area under the curves was calculated as well, and we expressed in \%. AUC without insulin was considered as $100 \%$.

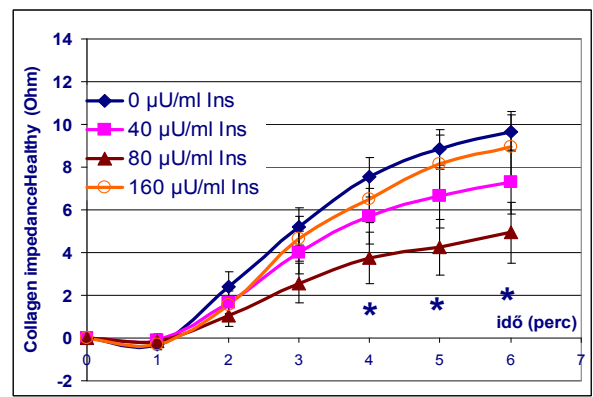

Fig. 19. Collagen induced aggregation in healthy volunteer's whole blood in the function of time, in the presence or absence of Actrapid insulin. A significant decrease occurred in the presence of $80 \mu \mathrm{U} / \mathrm{ml}$ of insulin

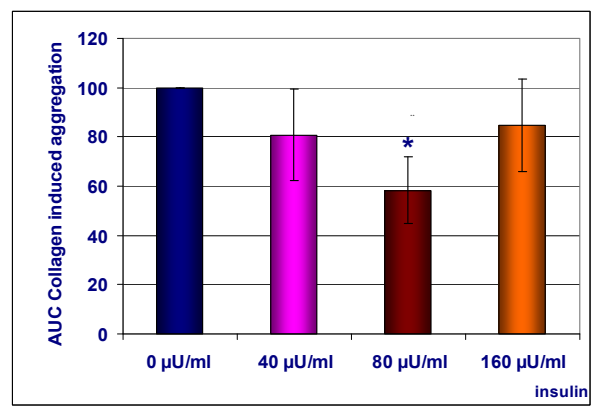

Fig. 20. AUC in healthy subjects. Significant decrease was detected in the presence of 80 $\mu \mathrm{U} / \mathrm{ml}$ of insulin, considering $100 \%$ of AUC without insulin 


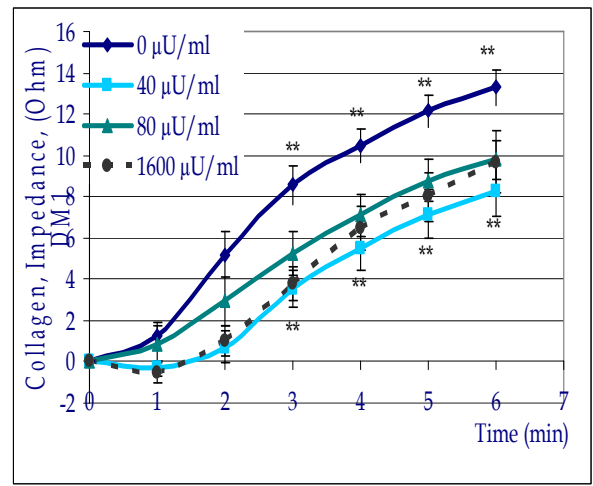

Fig. 21. Collagen induced platelet aggregation in the function of time on whole blood in DM1 patients. DM1 patient's blood was sensitive to each concentration of insulin, without any significant difference among the groups.

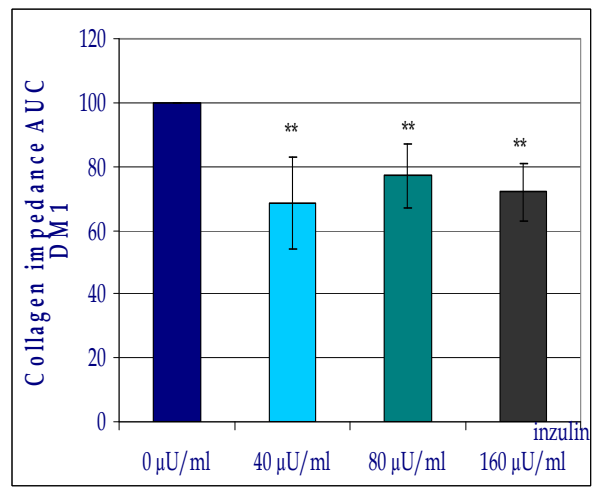

Fig. 22. AUC of collagen induced platelet aggregation curves in DM1. The three insulin concentration caused similar, but significant decrease in the aggregation.

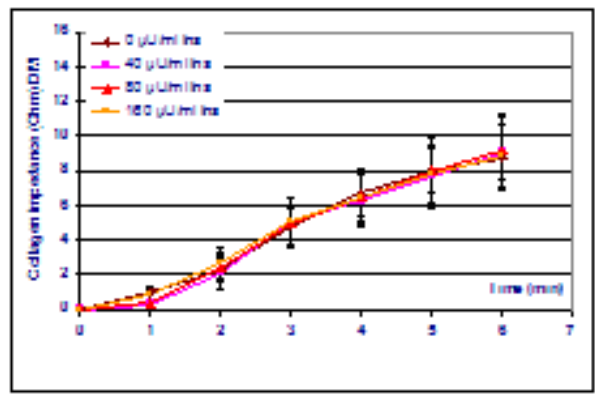

Fig. 23. Collagen induced platelet aggregation in DM2 patients. Insulin was ineffective on collagen induced platelet aggregation. 


\subsubsection{Effect of exogenous insulin on PMA induced ROS production in whole blood}

Insulin effect on the maximum of PMA induced ROS production was investigated, as well. The presence of insulin in whole blood was able to reduce PMA induced ROS production in whole blood in healthy subjects and that of DM1 patients' blood too, but not in DM 2 patients (Figure 24.)

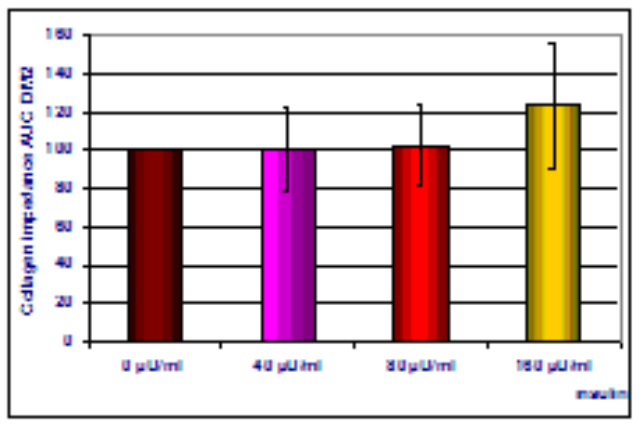

Fig. 24. Insulin was not able to reduce area under platelet aggregation curve in blood samples of patients with DM2.

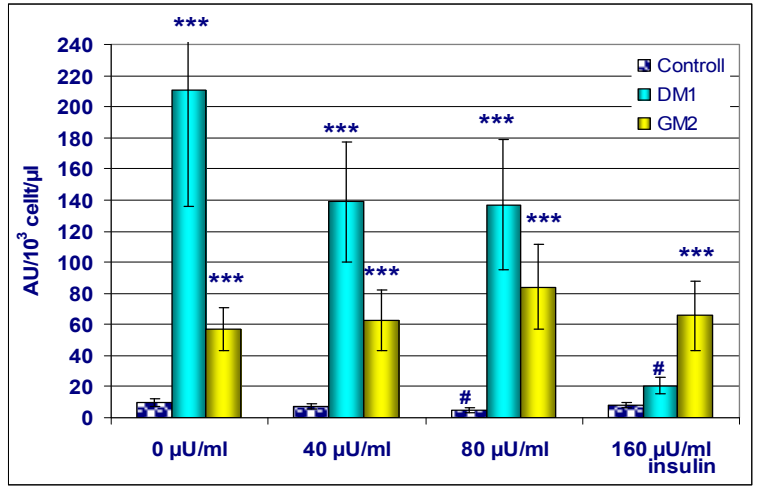

Fig. 25. Effect of insulin on PMA induced ROS production on whole blood of Control, DM1 and CM2 patients' whole blood, in vitro.

\subsection{Summary of data obtained from investigation of diabetic patients blood}

The presence of DM1 or DM2 diabetes differently influenced the thrombocyte function and antioxidant status of PAD patients, and the in vitro effects of insulin on collagen induced platelet aggregation and PMA induced ROS generation. 
Investigating platelet aggregation in whole blood of patients neither in ADP, nor in collagen induced aggregation curves differed significantly from each other or the control. Calculating area under curves (AUC), significant differences were revealed, showing that platelets of DM1 patients was more sensitive to both inductors than that of in other two groups (Figure 13-16). This increased sensitivity was accompanied by lower SOD activity (Figure 17.) and highly significant increase in PMA induced ROS generation (Figure 18.).

In vitro effects of insulin on collagen induced platelet aggregation, and PMA induced ROS generation were also investigated in the presence of $0,40,80,160 \mu \mathrm{U} / \mathrm{ml}$ insulin in the whole blood. A U-shaped inhibition in collagen induced aggregation was detected in healthy subjects, a constant decrease in DM1 patients, without dose dependence, but insulin was ineffective in DM2 patients blood (figure 19-25). The maximum values of PMA induced ROS generation was significantly higher than in other two groups, but insulin pre-treatment was able to reduce it. Insulin was able to reduce the low ROS levels were induced by PMA in the blood donor's blood, but not in DM2 patient's blood.

\section{Conclusion}

Reconstruction of blood flow in the formerly ischemic tissues induces chain reactions, which affect not only the tissues are involved, but threats the integrity of the whole organism, causing multiorgan failure and death. The irreversible muscle cell damage begins 3 hour after ischemia and completed about within 6 hours (Blaisdell W. 2002). Tissue damage induced by the revascularization surgery of lower limbs had been in the focus of our studies. Our main aims were to study and characterize the role of the duration of the hypoxia on the thrombocyte function, and on the other circulating cells, especially on the leukocytes. ADP and collagen were used as platelet aggregation inductors. ADP is able to potentate the effects of other inductors, such as thrombin, due to stimulate and stabilize the thrombus. Collagen appears in the blood steam in the course of the injury of endothelial lineage. Collagen directly acts due to GPIIbIIIa receptors, and indirectly by Von-Willebrand factor, induces platelet aggregation and increases the adherence of platelet to the vessel wall, too.

Our studies can be considered new, in the respects of the parallel measurement of aggregation in platelet rich plasma and in whole blood within the same samples, at the same time. We revealed significant differences using the two methods. In isolated thrombocyte the effectiveness of antiplatelet therapy can be tested directly on the thrombocyte itself, during the hospitalization. In whole blood, the modulating effects of other cellular and non cellular components of blood can be studied. The disturbances in antioxidant/prooxidant balance are in the background of this phenomenon. The most surprising results were in our studies, that in PRP a satisfactory aggregation inhibition was detected in both the Acute and Elective groups (Figure1 and 3), but in whole blood (Figure 3., 4.,5., 6.) a highly significant elevation in ADP and collagen induced aggregation were revealed in the Acute group, compared to the Elective and Control ones. We concluded that the increased leukocyte numbers, the elevated free radical production of the individual leukocytes, and the exhausted antioxidant capacity, mainly the significant reduction in SOD activity, had important role (Figure 7. and 8). We pointed out the importance of the increase of 
prooxidants, while antioxidant capacity decreases especially in Acute group and in a less extensive way in Elective group too.

It has to be mentioned that SOD deficiency is a highly important determinant of the increased ROS production and the increase in platelet aggregation one week after the surgery. Pipinos and co-workers published that, the SOD enzyme mutation of gastrocnemius muscle of rats is a risk factor of PAD, (Pipinos II and Swanson SA 2008). Intracellular GSH and the plasma - $\mathrm{SH}$ groups possess remarkable antioxidant capacities. Before the surgery their levels were almost equal in the three groups, but after surgery a small but significant transient reduction was measured in their levels, mainly in the Acute group. Conflicting results are published about the effects of volatile anaesthetics on oxidative stress, and some local anaesthetics can cause transient decrease in GSH level in skeletal muscles (Jia-Li Luo, et al 1996). It can be supposed that transient decrease in GSH level is partially caused by the surgical intervention. Further alterations are caused by the disease itself, due to the sclerotic vessels, and/or the presence of hypertension, and other disturbances. These states also complicated by increased free radical generation, which usually increased further by the surgical intervention. Activated platelets play definitive role in the development of atherosclerosis and increase of the risk of surgical interventions. In spite of these there are only few data which can highlight the background of the poor prognosis of PAD and the role of thrombocytes in these processes. Other risk-factors which have definitive role, the activated complement system (Beinrohr L), leukocyte-thrombocyte interaction, and the increased endothelin release. The consequences of IR affect not only the great conduit vessels, but microcirculation is also affected (Kaszaki et al 2006). In the course of the animal studies they improved the protective effects of endothelin-A receptor antagonists and preconditioning against IR induced micro-vascular alterations.

Diabetes is also a well defined risk factor which worsens the outcome the surgical intervention. In the second series of our study thrombocyte function and antioxidant prooxidant status of diabetic patients with peripheral arterial disease were investigated and effects of exogenous insulin were tested. Platelet aggregation of PRP in diabetic patients was reduced compared to healthy blood donors signing the efficacy of their antiplatelet treatment. This difference failed to appear in whole blood. Free radical productions were significantly higher and SOD enzyme activities were significantly lower in diabetic patients compared to control. Low concentrations of insulin reduced the aggregation and free radical production in healthy and Type 1 diabetic patient's blood but failed to induce such effects in Type 2 diabetic ones. Insulin resistance is developed against not only the metabolic effects of insulin, but against other activities of this important hormone, as well. Revealing the alterations caused by surgical intervention in the function of circulating cells is inevitably important to improve the outcome of these procedures and reduce the complication of surgical intervention and facilitate recovery. Insulin is a vital hormone which essential for the glucose uptake of skeletal muscle and the heart. Insulin resistance increases the harmful effect of IR. Insulin effect can be improved and free radical production can be decreased by antioxidant, signing the important roles of free radicals in the pathogenesis of IR. Mice overexpressing extracellular SOD are less sensitive to IR (Sheng H et al 1999), signing that endogenous antioxidants have important role in tissue protection. 
Present study support the importance of antioxidant prooxidant equilibrium and the role of endogenous antioxidants.

\section{References}

Adiseshiah M, Round JM, Jones DA. Reperfusion injury in skeletal muscle: a prospective study in patients with acute limb ischaemia and claudicants treated by revascularization. Br J Surg. 1992. 79. (10) 1026-10269.

Alsousou J, Thompson M, Hulley P, Noble A, Willett K. The biology of platelet-rich plasma and its application in trauma and orthopaedic surgery: a review of the literature. J Bone Joint Surg Br. 91(8):987-96.2009.

Arato E, Kurthy M, Jancso G, Sinay L, Kasza G, Verzar Z, Benko L, Cserepes B, Kollar L, Roth E. [Oxidative stress and leukocyte activation after lower limb revascularization surgery] Magy Seb. 59. (1):50-57.2006.

Arató E, Kürthy M, Sínay L, Kasza G, Menyhei G, Hardi P, Masoud S, Ripp K, Szilágyi K, Takács I, Miklós Z, Bátor A, Lantos J, Kollár L, Roth E, Jancsó G. Effect of vitamin $\mathrm{E}$ on reperfusion injuries during reconstructive vascular operations on lower limbs Clin Hemorheol Microcirc. 44. (2):125-36.2010.

Arató E., Kürthy M., Jancsó G., Kasza G., Sinay L., Rozsos I., Kollár L., Rõth E.: [Role of oxidative stress in revascularization surgery in lower limb] Az oxidatív stressz szerepe az alsóvégtagi revaszkularizációs szindrómában. Érbetegségek, S2; 39. 2005.

Arató E, Kürthy M, Sínay L, Kasza G, Menyhei G, Masoud S, Bertalan A, Verzár Z, Kollár L, Roth E, Jancsó G. Pathology and diagnostic options of lower limb compartment syndrome. Clin Hemorheol Microcirc. 41.(1):1-8.2009.

Arató E, Kürthy M, Sínay L, Kasza G, Menyhei G, Hardi P, Masoud S, Ripp K, Szilágyi K, Takács I, Miklós Z, Bátor A, Lantos J, Kollár L, Roth E, Jancsó G. Effect of vitamin E on reperfusion injuries during reconstructive vascular operations on lower limbs. Clin Hemorheol Microcirc. 44(2):125-36.2010a.

Arató et al 2010b E, Kürthy M, Sínay L, Kasza G, Menyhei G, Hardi P, Masoud S, Ripp K, Szilágyi K, Takács I, Miklós Z, Bátor A, Lantos J, Kollár L, Roth E, Jancsó $G$. Effect of vitamin $\mathrm{E}$ on reperfusion injuries during reconstructive vascular operations on lower limbs. Clin Hemorheol Microcirc. 44(2):125$36.2010 \mathrm{~b}$

Bakkaloglu C, Soyagir B, Torun M, Karagoz H, Simsek B. Oxidative stress is decreased in off-pump versus on-pump coronary artery surgery. J Biochem Mol Biol. 31;39(4):377-82. 2006.

Beinrohr L, Dobó J, Závodszky P, Gál P. C1, MBL-MASPs and C1-inhibitor: novel approaches for targeting complement-mediated inflammation. Trends Mol Med. 14(12):511-21. 2008.

Blaisdell W. The pathophysiology of skeletal muscle ischemia and the reperfusion syndrome: a review Cardiovascular Surgery, 10, (6). 620-630, 2002.

Born G.V.Haslam RJ, Goldman M. Nature. 13;205:678-80. 1965.

Born, G.V.R. Platelets in thrombogenesis: mechanism and Inhibition of platelet aggregation Ann R Coll Surg Engl. 36:200-6 1965. 
Brennan ML, Penn MS, Van Lente F, Nambi V, Shishehbor MH, Aviles RJ, Goormastic M, Pepoy ML, McErlean ES, Topol EJ, Nissen SE, Hazen SL. Prognostic value of myeloperoxidase in patients with chest pain. N Engl J Med. 349(17):1595604.2003 .

Brevetti G, Schiano V, Laurenzano E, Giugliano G, Petretta M, Scopacasa F, and Chiariello M. Myeloperoxidase, but not C-reactive protein, predicts cardiovascular risk in peripheral arterial disease Eur Heart J. 29: 224-230. 2008.

Buchholz AM, Bruch L, Schulte KL. Activation of circulating platelets in patients with peripheral arterial disease during digital subtraction angiography and percutaneous transluminal angioplasty. Thromb Res. 109(1):13-22. 2003.

Claesson K, Kölbel T, Acosta S. Role of endovascular intervention in patients with diabetic foot ulcer and concomitant peripheral arterial disease. Int Angiol. 30 (4):349-58. 2011.

Combined thrombolysis with abciximab favourably influences platelet-leukocyte interactions and platelet activation in acute myocardial infarction. J Thromb Thrombolysis. 20(3):155-61.2005.

Comparative effectiveness of adenosine analogues as inhibitors of blood-platelet aggregation and as vasodilators in man. Nature. 13;205:678-80. 1965

Downey JM, and Cohen MV. Free radicals in the heart: friend or foe? Expert Rev Cardiovasc Ther. 6(5):589-91.2008.

Dröge W, Free Radicals in the Physiological Control of Cell Function Physiological Review 82 47-95. 2002.

Falkensammer J, Oldenburg WA. Surgical and medical management of mesenteric ischemia. Curr Treat Options Cardiovasc Med. 8(2): 137-143.2006.

Ferencz A, Szanto Z, Kalmar-Nagy K, Horvath OP, Roth E. Mitigation of oxidative injury by classic and delayed ischemic preconditioning prior to small bowel autotransplantation. Transplant Proc. 2004. 36. (2) 286-288. 2004.

Foo F, Oldroyd KG. Clinical value of antiplatelet therapy in patients with acute coronary syndromes and in percutaneous coronary intervention. Biomark Med. 5(1):930.2011.

Henrich M, Paddenberg R, Haberberger RV, Scholz A, Gruss M, Hempelmann G, Kummer $\mathrm{W}$. Hypoxic increase in nitric oxide generation of rat Sensory neurons requires activation of mitochondrialComplex ii and voltage-gated calcium channels Neuroscience.;128(2):337-45.2004.

Ingerman-Wojenski CM, Silver MJ. A quick method for screening platelet dysfunctions using the whole blood lumi-aggregometer. Thromb Haemost. 51(2):154-6. 1984.

J Interv Cardiol. 14(5):539-546. 2001.

Jia-Li Luo, Folke Hammarqvist, Kerstin Andersson, Jan Wernerman Skeletal Muscle Glutathione After Surgical trauma Annals of Surgery 223, (4) 420-427. 1996.

Jude EB, Oyibo SO, Chalmers N, Boulton AJPeripheral arterial disease in diabetic and nondiabetic patients: a comparison of severity and outcome. Diabetes Care. 24(8):1433-7.2001. 
Kathy K. Griendling; Dan Sorescu; Bernard Lassègue; Masuko Ushio-Fukai Modulation of Protein Kinase Activity and Gene Expression by Reactive Oxygen Species and Their Role in Vascular Physiology and Pathophysiology Arteriosclerosis, Thrombosis, and Vascular Biology.20:2175-2183. 2000.

Kaszaki J, Wolfárd A, Szalay L, Boros M. Pathophysiology of ischemia-reperfusion injury. Transplant Proc. 2006 Apr;38(3):826-8.

Kato H, Kogure K.: Biochemical and molecular characteristics of the brain with developing cerebral infarction. Cell Mol Neurobiol. 19. (1):93-108. 1999

Kolamunne RT, Clare M, Griffiths HR. Mitochondrial superoxide anion radicals mediate induction of apoptosis in cardiac myoblasts exposed to chronic hypoxia. Arch Biochem Biophys.505(2):256-65. 2011.

Krumholz HM, Goldberger AL. Reperfusion arrhythmias after thrombolysis. Electrophysiologic tempest, or much ado about nothing. Chest. 99 (4 Suppl):135S140S.1991.

Laird JR. The management of acute limb ischemia: techniques for dealing with thrombus.

Levy JH, Tanaka KA. Inflammatory response to cardiopulmonary bypass. Ann Thoracic Surgery. 75.(2):S715-20.2003.

Li W, Khor TO, Xu C, Shen G, Jeong WS, Yu S, Kong AN. Activation of Nrf2-antioxidant signaling attenuates NFkappaB-inflammatory response and elicits apoptosis. Biochem Pharmacol. 76(11):1485-9. 2008.

Lin JK, Shih CA. Inhibitory effect of curcumin on xanthine dehydrogenase/oxidase induced by phorbol-12-myristate-13-acetate in NIH3T3 cells. Carcinogenesis. 15.:171771.1994

Loberg AG, Stallard J, Dunning J, Dark J. Can leukocyte depletion reduce reperfusion injury following cardiopulmonary bypass? Interact Cardiovasc Thorac Surg. 12(2):232-7. 2011.

Massberg S., Enders G, Leiderer R, Eisenmenger S, Vestweber D, Krombach K, Messmer K. Platelet-Endothelial Cell Interactions During Ischemia/Reperfusion: The Role of PSelectin Blood 92. (2) 507-515. 1998.

Mhairi J. Maxwell, Erik Westein, Warwick S. Nesbitt, Simon Giuliano, Sacha M. Dopheide P. Jackson Identification of a 2-stage platelet aggregation process mediating sheardependent thrombus formation Blood 109. 566-576. 2007.

Ming Wei Liu, Gary S. Roubin and Spencer B. King III Restenosis After Coronary Angioplasty Potential Biologic Determinants and Role of Intimal Hyperplasia Circulation 79:1374-1387.1989.

Misra HP, Fridovich I. The role of superoxide anion in the autoxidation of epinephrine and a simple assay for superoxide dismutase. J Biol Chem. 247(10):3170-5. 1972.

Misty M. Payne Charles, Theodore Dotter The Father of Intervention Tex Heart Inst J. 28(1): 28-38.2001.

Moens AL, Claeys MJ, Timmermans JP, Vrints CJ. Myocardial ischemia/reperfusion-injury, a clinical view on a complex pathophysiological process. Int J Cardiol. 2005 Apr 20;100(2):179-190. 
Moncada S, Palmer RM, Higgs EA. Nitric oxide: physiology, pathophysiology, and pharmacology. Pharmacol Rev. (2):109-42. 1991.

Ohkawa H, Ohishi N, Yagi K. Assay for lipid peroxides in animal tissues by thiobarbituric acid reaction. Anal Biochem 95(2):351-8. 1979.

Peto K, Nemeth N, Brath E, Takacs IE, Baskurt OK, Meiselman HJ, Furka I, Miko I. The effects of renal ischemia-reperfusion on hemorheological factors: preventive role of allopurinol. Clin Hemorheol Microcirc. 37(4):347-58.2007.

Pipinos II, Swanson SA, Zhu Z, Nella AA, Weiss DJ, Gutti TL, McComb RD, Baxter BT, Lynch TG, Casale GP. Chronically ischemic mouse skeletal muscle exhibits myopathy in association with mitochondrial dysfunction and oxidative damage. Am J Physiol Regul Integr Comp Physiol.;295(1):R 290-296. 2008

$\mathrm{R}$ Hille and T Nishino Flavoprotein structure and mechanism. 4. Xanthine oxidase and xanthine dehydrogenase The FASEB Journal, 9, 995-1003.

Röth E, Hejjel L: Oxygen free radicals in the heart disease, In:Cardiac Drug Development Guide. ED. M.K. Pugsley. Human Press Inc. Totowa NJ. 47-66. 2003.

Ruiter MS, van Golde JM, Schaper NC, Stehouwer CD, Huijberts MS. Diabetes impairs arteriogenesis in the peripheral circulation: review of molecular mechanisms. Clin Sci 8;119(6):225-38.2010.

Sedlak J, Lindsay RH. Estimation of total, protein-bound, and nonprotein sulfhydryl groups in tissue with Ellman's reagent. Anal Biochem. 24;25(1):192-205. 1968.

Sinay L, Kürthy M, Horváth S, Arató E, Shafiei M, Lantos J, Ferencz S, Bátor A, Balatonyi B, Verzár Z, Süto B, Kollár L, Wéber G, Roth E, Jancsó G. Ischaemic postconditioning reduces peroxide formation, cytokine expression and leukocyte activation in reperfusion injury after abdominal aortic surgery in rat model. Clin Hemorheol Microcirc. 40(2):133-42.2008.

Smyth SS, McEver RP, Weyrich AS, Morrell CN, Hoffman MR, Arepally GM, French PA, Dauerman HL, Becker RC; 2009. Platelet Colloquium Participants. Platelet functions beyond hemostasis. J Thromb Haemost. 7. (11):1759-66. 2009.

Szabo S, Etzel D, Ehlers R, Walter T, Kazmaier S, Helber U, Hoffmeister HM.

Umar S, van der Laarse A. Nitric oxide and nitric oxide synthase isoforms in the normal, hypertrophic, and failing heart. Mol Cell Biochem. 333 .(1-2):191-201. 2010.

Vinten-Johansen J, Zhao ZQ, Jiang R, Zatta AJ, Dobson GP. Preconditioning and postconditioning: innate cardioprotection from ischemia-reperfusion injury.Journal of Applied Physiology 103. 1441-1448. 2007.

Virchow R. Gesammelte Abhandlungen zur Wissenschaftlichen Medicin. Frankfurt, Germany: Medinger Sohn \& Co.; 219-732.1856.

Weiss A.G and Zahger AT: Coronary angioplasty or intravenous thrombolysis: the dilemma of optimal reperfusion in acute myocardial infarction: A critical review of the literature. J Thromb. Thrombolysis 8(2):113-21. 1999.

Xia Y and Zeier J.L. Analytical Biochemistry 245, 1, 93-96, 1997. 
Yassin MM, Harkin DW, Barros D'Sa AA, Halliday MI, Rowlands BJ. Lower limb ischemiareperfusion injury triggers a systemic inflammatory response and multiple organ dysfunction. World J Surg. 6(1):115-21.2002.

Sheng H, Bart RD, Oury TD, Pearlstein RD, Crapo JD, Warner DS. Mice overexpressing extracellular superoxide dismutase have increased resistance to focal cerebral ischemia. Neuroscience. 88. (1): 185-91.199 


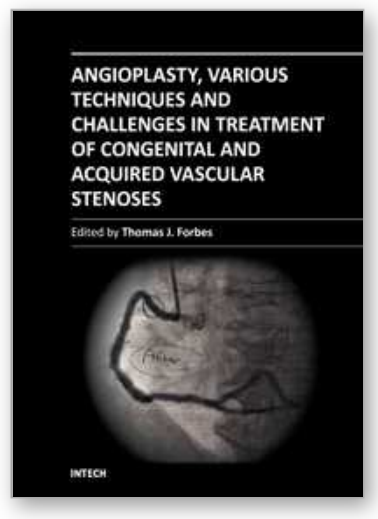

\section{Angioplasty, Various Techniques and Challenges in Treatment of Congenital and Acquired Vascular Stenoses}

Edited by Dr. Thomas Forbes

ISBN 978-953-51-0084-3

Hard cover, 236 pages

Publisher InTech

Published online 14, March, 2012

Published in print edition March, 2012

The field of performing transcatheter interventions to treat vascular lesions has exploded over the past 20 years. Not only has the technology changed, especially in the arena of balloon/stent devices, but the techniques of approaching complex lesions has evolved over the past decade. Lesions that no one would have imagined treating back in the 1990's are now being done routinely in the catheterization suite. This book provides an update on the current techniques and devices used to treat a wide variety of lesions. Though, at first, the outward appearance of the topics appears to be varied, they are all related by the common thread of treating vascular lesions. We hope, by publishing this book, to accomplish two things: First, to offer insight from experts in their field to treat, both medically and procedurally, complex vascular lesions that we frequently encounter. Secondly, we hope to promote increased communication between areas of medicine that frequently don't communicate, between adult interventional cardiologists, pediatric interventional cardiologists, interventional radiologists, and neurosurgeons. Much can be learned from our respective colleagues in these areas which can further our own world of interventions.

\section{How to reference}

In order to correctly reference this scholarly work, feel free to copy and paste the following:

Maria Kurthy, Gabor Jancso, Endre Arato, Laszlo Sinay, Janos Lantos, Zsanett Miklos, Borbala Balatonyi, Szaniszlo Javor, Sandor Ferencz, Eszter Rantzinger, Dora Kovacs, Viktoria Kovacs, Zsofia Verzar, Gyorgy Weber, Balazs Borsiczky and Erzsebet Roth (2012). Investigation of the Oxidative Stress, the Altered Function of Platelets and Neutrophils, in thePatients with Peripheral Arterial Disease, Angioplasty, Various Techniques and Challenges in Treatment of Congenital and Acquired Vascular Stenoses, Dr. Thomas Forbes (Ed.), ISBN: 978-953-51-0084-3, InTech, Available from: http://www.intechopen.com/books/angioplasty-varioustechniques-and-challenges-in-treatment-of-congenital-and-acquired-vascular-stenoses/investigation-ofoxidative-stress-and-the-altered-function-of-platelets-and-neutrophils-in-the-patie

\section{INTECH}

open science | open minds

\section{InTech Europe}

University Campus STeP Ri

Slavka Krautzeka 83/A

51000 Rijeka, Croatia

Phone: +385 (51) 770447

\section{InTech China}

Unit 405, Office Block, Hotel Equatorial Shanghai

No.65, Yan An Road (West), Shanghai, 200040, China

中国上海市延安西路65号上海国际贵都大饭店办公楼 405 单元

Phone: +86-21-62489820 
Fax: +385 (51) 686166

Fax: +86-21-62489821

www.intechopen.com 
(C) 2012 The Author(s). Licensee IntechOpen. This is an open access article distributed under the terms of the Creative Commons Attribution 3.0 License, which permits unrestricted use, distribution, and reproduction in any medium, provided the original work is properly cited. 